\title{
Immunotherapy of Human Papilloma Virus Induced Disease
}

\author{
Sjoerd H. van der Burg ${ }^{*}$ \\ Department of Clinical Oncology, Leiden University Medical Center, Leiden, The Netherlands
}

\begin{abstract}
Immunotherapy is the generic name for treatment modalities aiming to reinforce the immune system against diseases in which the immune system plays a role. The design of an optimal immunotherapeutic treatment against chronic viruses and associated diseases requires a detailed understanding of the interactions between the target virus and its host, in order to define the specific strategies that may have the best chance to deliver success at each stage of disease. Recently, a first series of successes was reported for the immunotherapy of Human Papilloma Virus (HPV)-induced premalignant diseases but there is definitely room for improvement. Here I discuss a number of topics that in my opinion require more study as the answers to these questions allows us to better understand the underlying mechanisms of disease and as such to tailor treatment.
\end{abstract}

Keywords: Innate immune signaling, CD4 T cells, interferon-gamma, macrophages, cervical cancer, oropharyngeal cancer, adoptive cell transfer.

\section{WHAT DO WE KNOW ABOUT THE IMMUNE RESPONSE TO HPV?}

In a recent review of the literature I argued that HPV can be classified into a group of persistent DNA viruses with low antigenic drift, which includes Epstein Barr virus (EBV), Cytomegalovirus (CMV) and Hepatitis B virus (HBV) for which the presence of a virus-specific $\mathrm{T}$-cell response is important for the final outcome of infection. The control of these viral infections require an effective $\mathrm{T}$-cell response comprising both virus-specific $\mathrm{CD}^{+} \mathrm{CTL}$ and $\mathrm{CD}^{+}$IL$2 / \mathrm{IFN} \gamma$-producing Th1 cells. The Th1 cells are required to license the priming of virus-specific $\mathrm{CD}^{+} \mathrm{T}$ cells, to sustain the fitness of virus-specific $\mathrm{CD} 8^{+} \mathrm{T}$ cells and to modulate the local virus-infected or transformed microenvironment for it to attract $\mathrm{CD}^{+} \mathrm{T}$ cells [1]. It has been long known that $\mathrm{T}$ cells, and $\mathrm{CD}^{+} \mathrm{T}$ cells in particular, play an important role in the protection against HPV [2]. In an attempt to put the knowledge about HPV-specific T-cell response in health and disease as well as how it may affect therapeutic vaccination into perspective, the most recent literature was reviewed [3]. Summarized, in healthy individuals one can detect circulating HPV16-specific $\mathrm{CD}^{+}$type 1 (Th1) and type $2 \mathrm{~T}$ helper (Th2) cells and $\mathrm{CD}^{+}$cytotoxic $\mathrm{T}$ lymphocytes (CTLs) that are reactive to a broad array of epitopes in the viral early (E2, E6, E7) and late antigens (L1) and are able to migrate to areas where viral antigen is presented [4-8]. Furthermore, spontaneous regression of an HPV-induced lesion is associated with the presence of circulating CD4+ and CD8+ T cells specific for HPV early antigens and coincident with the infiltration of the lesion by $\mathrm{CD} 8^{+} \mathrm{CTLs}$ and $\mathrm{CD} 4{ }^{+} \mathrm{T}$ cells that outnumber $\mathrm{CD} 25^{+}$regulatory $\mathrm{T}$ cells (Tregs) [9-14]. Moreover, in patients with progressive disease the presence of an HPV-specific Th1 response is

*Address correspondence to this author at Department of Clinical Oncology, Leiden University Medical Center, Leiden, The Netherlands;

Tel: +31 71526 1180; E-mail: shvdburg@lumc.nl associated with a better clinical course as well as with a better response to treatment [15-18].

However, in most individuals the presence of HPVinduced progressive disease corresponds with a nondemonstrable or weak T-cell response to the HPV early antigens in the blood [4,5,19-21]. This lack of reactivity is also reflected locally as HPV-specific T cells can be detected in some high-grade squamous intraepithelial lesions (HSILs) and among about one third of the populations of tumorinfiltrating lymphocytes (TILs) in patients with cancer $[19,21,22]$. The functional activity of these local HPVspecific T cells are likely to be suppressed as TILs may lack cytotoxicity [23] and/or express co-inhibitory molecules such as Programmed Death-1 (PD-1) [24] as well as CD94 and NKG2a [25] at their cell surface. Local immune suppression is also evident from the loss of locally present IFN $\gamma$ [26-28] and an increase in IL-10 [26,28,29] that is also detected in the serum [30]. In addition, $\mathrm{T}$ cells expressing TGF $\beta$ have been detected in HPV-induced lesions [26]. These cytokines may directly suppress HPV-specific immunity since IL-10 can potently inhibit the production of pro-inflammatory cytokines and TGF- $\beta$ has a potent negative effect on the proliferation and Th1-differentiation of $\mathrm{T}$ cells [31]. Notably, IL-10 producing HPV-specific Tregs, highly capable of inhibiting the proliferation and cytokine (IFN $\gamma$ and IL-2) production of recently activated naïve $\mathrm{CD} 4^{+} \mathrm{T}$ cells, Th1 cells and CTL, have been isolated from premalignant tissues and cancer $[19,32]$ indicating that part of the local immune suppression may come from a erroneously polarized HPV-specific T-cell response. The number of Tregs are increased in HPV-induced tumors $[26,33]$ probably attracted by tumor-produced CXCL12 [34]. Inside the tumor, these cells can have a major clinical impact since the ratio between tumor-infiltrating $\mathrm{CD}^{+} \mathrm{T}$ cells and Foxp $3^{+}$Tregs proved to be an independent prognostic factor in cervical carcinoma [35]. Increased number of Tregs are also found in tumor draining lymph nodes [36]. 
In view of this, treatments that attempt to increase the level of strongly activated local HPV-specific type 1 Th-cells and CTL through local immune stimulation, vaccination or the adoptive transfer of HPV-specific T cells are logical.

\section{A GLEAM OF SUCCESS; WHERE FAILURE IS DEFAULT}

Stimulation of local immunity by the use of imiquimod (Aldara $\left.{ }^{\circledR}\right)$ applied to the surface of the epithelium results in type I interferon signaling of keratinocytes and a strong infiltration of the treated tissue by CXCR3 (Th1) lymphocytes [37]. Treatment of HPV-induced high grade lesions of the vulva (VIN3) resulted in viral clearance, normalization of immune cell infiltrate to the level in healthy tissue and a complete regression of the lesion in a substantial number of patients [38,39]. The imiquimod-induced complete regressions were associated with the presence of circulating HPV-specific Th1 cells [18], suggesting that HPV-specific immunity plays a role in the success of this treatment. Non-responsiveness, however, was associated with the local presence of Tregs [40]. An HPV16 synthetic long E6 and E7 peptide vaccine (HPV16 SLP) and a L2E6E7 fusion protein vaccine (TA-CIN), both aiming to induce $\mathrm{HPV}$-specific $\mathrm{CD}^{+}$and $\mathrm{CD}^{+}{ }^{\mathrm{T}}$-cell responses, had clinical success in VIN3 patients either by itself or when given in combination with imiquimod pretreatment [41-43]. The aggregated immunomonitoring data of these vaccine trials paint the picture that clinical success was achieved when strong HPV-specific IFN $\gamma$-associated T-cell responses were induced and when locally the number of infiltrating $\mathrm{CD}^{+}$ and $\mathrm{CD}^{+} \mathrm{T}$ cells was enhanced. At the other hand, nonresponsiveness was associated with weaker and HPV16specific T-cell responses to lower number of epitopes as well as vaccine-mediated increases in the numbers of circulating HPV-specific Tregs and an increased density of Tregs in the lesion [41-43]. The HPV16 SLP vaccine was also capable of inducing significant T-cell responses in patients with cancer $[44,45]$, albeit not to the level observed in patients with high grade vulvar disease and without clinical reactivity. Notably, in a small study two cases with early recurrence showed an increase in HPV-specific Tregs after vaccination [45]. Neither with these vaccines nor with any other vaccine has therapeutic vaccination resulted in the cure of patients with well-established large premalignant HPV-induced lesions or tumors [3]. In analogy to the successes obtained with treating melanoma patients $[46,47]$ adoptive transfer HPV-specific T cells into patients with HPV-induced cancer is now under consideration. The first results in my laboratory suggest that it is possible to consistently obtain HPV-specific effector T cells from patients with cervical cancer under full GMP conditions (van Poelgeest \& van der Burg, unpublished observations). Accumulated data of studies on the local environment reveals the presence of different types of immune evasion mechanisms which may hamper the efficacy of current therapies. This advocates combining current strategies with other modalities. For instance, one may combine current vaccines with stronger adjuvants such as IFN $\alpha$ to selectively boost the Th1 response. In addition, combinations with chemotherapy not only to lower tumor load but also to get rid of Tregs and/or other immune suppressive cells can be applied. Other strategies may include the infusion of blocking antibodies against co- inhibitory molecules or the adoptive transfer of HPVspecific T cells and combinations between all of these [3].

\section{QUESTIONS WAITING TO BE ADDRESSED}

The insights into the interactions between the immune system and HPV as well as the diseases it causes has allowed us to begin to understand why current immunotherapeutic efforts are successful or fail. Yet there are still many nagging questions that come to mind. In my opinion these are worthwhile to answer as it may help us to better understand this disease and as such the treatment required at each stage of disease.

The first question revolves around the relative importance of either CD4+ $\mathrm{T}$ cells or $\mathrm{CD}^{+} \mathrm{T}$ cells in the protection of the host. The well-known role of $\mathrm{CD}^{+} \mathrm{T}$ cells in virus infections is to promote B-cell antibody production and to promote the priming, licensing and sustainment of function of virus-specific CTLs. Virus-specific $\mathrm{CD}^{+}$and $\mathrm{CD}^{+} \mathrm{T}$ cells are readily detected with the new state-of-theart immunomonitoring technologies. The measurement of HPV16-specific T-cell immunity has generally been more difficult than that for other viruses. The detection of HPV16specific CD8 $+\mathrm{T}$ cells have been found to be notoriously difficult and required at least one round of in vitro stimulation before detection. Positive responses were found in HPV16-positive patients at all stages of disease but not in healthy subjects [48-51]. In addition, such responses are more often found in HVP16-positive women without CIN than with $\mathrm{CIN}[5,8]$. HPV16-specific $\mathrm{CD}^{+}$T-cell responses can be detected directly ex-vivo in the blood of both healthy individuals and in patients at different stages of disease $[4,52,53]$. In healthy individuals the magnitude of the HPV16-specific $\mathrm{CD}^{+}$Th1 response is in the range of that detected against influenza virus [53]. This poses the question whether the response of $\mathrm{CD}^{+} \mathrm{T}$ cells to $\mathrm{HPV}$ is more important than $\mathrm{CD}^{+} \mathrm{T}$ cells in the protection against developing HPV-induced lesions. Strong $\mathrm{CD}^{+}$T-cell mediated protection against viruses has been described in several animal models of infection [54]. In example, $\mathrm{CD}^{+} \mathrm{T}$ cells controlled acute infection and reduced the number of cells latently infected in the absence of $\mathrm{CD} 8+\mathrm{T}$ cells or $\mathrm{B}$ cells with murine gammaherpesvirus infection [55]. Similarly $\mathrm{CD}^{+}$IFN $\gamma$-producing $\mathrm{T}$ cells protected against a lethal challenge of genital herpes simplex virus type 2 in $\mathrm{CD}^{+} \mathrm{T}$-cell and B-cell deficient mice [56]. Furthermore, $\mathrm{CD}^{+}$Th1 cells were capable of protecting the host via the production of IFN $\gamma$ and direct cytotoxicity in infections with West Nile virus or Friend retrovirus [57,58]. There is no animal model for HPV16 infection but in the successful immunotherapy of HPV16-induced vulvar lesions there is a role for HPV16-specific $\mathrm{CD}^{+}{ }^{+} \mathrm{IFN} \gamma \mathrm{T}$-cell responses while CD8 T-cell reactivity again was much lower and did not show correlation with disease control [18,41-43]. In addition, only certain HLA class II alleles are consistently positively or negatively associated with disease progression in epidemiological studies $[101,102]$. This sustains the notion that Th1 cells may form the major protective force at this stage. If so, one may ask how these HPV16-specific Th1 cells accomplish this control. Epithelial cells can upregulate HLA class II after exposure to IFN $\gamma$ whereas the majority $(>80 \%)$ of cervical carcinomas constitutively express HLA class II [59]. As a consequence $\mathrm{CD}^{+} \mathrm{T}$-cells can recognize 
their cognate HLA class II presented epitope. $\mathrm{CD}^{+} \mathrm{T}$ cells are known to directly recognize virus infected epithelial cells to mediate viral control, partially via the killing of these cells [60,61]. Do HPV16-specific $\mathrm{CD}^{+} \mathrm{T}$ cells directly interact with infected keratinocytes? In principle they can but this topic still awaits further study. In addition, $\mathrm{CD} 4^{+} \mathrm{T}$ cells may indirectly affect infection through the IFN $\gamma$-mediated activation of innate immune cell populations. On the other hand, the protection against a progressive clinical course of HPV-induced tumors is more likely to depend on $\mathrm{CD} 8^{+} \mathrm{T}$ cell immunity [33]. These tumors are known to down regulate HLA class I. Furthermore, the ratio between $\mathrm{CD} 8^{+}$ and regulatory $\mathrm{T}$ cells is an independent prognostic factor [35]. There is no direct relation with survival and the number of $\mathrm{CD}^{+} \mathrm{T}$ cells although IFN $\gamma$-producing HPV-specific $\mathrm{CD}^{+}$can be isolated from a high number of tumors $[21,22]$. Potentially, they may also help in attracting the $\mathrm{CD} 8^{+} \mathrm{T}$ cells [62].

The second question concerns a topic that I call the lateearly antigen disparity. A number of studies have assessed HPV16 L1-specific $\mathrm{CD}^{+}$T-cell reactivity in healthy controls and in patients at different stages of disease with the outcome that the majority of controls and patients displayed proliferative T-cell responses $[63,64]$ associated with the production of IFN $\gamma[65,66]$. In a direct comparison, the Tcell response to the early antigens was less frequent and generally not associated with the production of IFN $\gamma$ in patients with HSIL or cancer [66]. At the one hand this suggests that the HPV16 L1-specific CD4 ${ }^{+} \mathrm{T}$-cell response is not associated with protection against HPV16 infection and associated disease. A notion that is confirmed by the observation that preventive vaccines, albeit capable of inducing strong L1-specific T-cell responses [66,67], are not capable of resolving existing infections [68]. In addition, most of the patients with cancer display L1-specific Th1 cells [66] and L1 is clearly present in cervical cancer cells [69]. On the other hand, it indicates that patients do not have intrinsic problems to mount a strong Th1 type of response to HPV16 suggesting that the presentation of late and early antigens to the immune systems differs with respect to the stimulatory context. As professional antigen presenting cells (APC) sit within the epithelium where their dendrites protrude the layers of epithelial cells it is logical to assume that upon uptake of free viral particles enough L1 protein is available for the processing machinery to allow the production of viral epitopes that can be presented in sufficient quantities to $T$ cells [70]. The early antigens can only be produced after successful infection of the cells in the basal cell layer. These antigens then have to be released to the immune system. Evidently, this does happen considering the high percentage of healthy individuals mounting a response to these antigens $[4,52,53]$. However, there is a substantial amount of data suggesting that many of the patients with HPV16-induced disease do not develop a $\mathrm{CD}^{+}$ T-cell response to the early antigens, unless invasive events occur $[16,19,20,71]$. The question that arises is why some individuals fail to produce an effective T-cell response to the early antigens of HPV but are capable to respond to the late antigen? Potential non mutually exclusive explanations for this phenomenon that come to mind are: 1) This is due to a lack of sufficient amounts of early antigen processed and presented for instance because only a few cells are productively infected, 2) There could be a difference in the immunological context in which these antigens are presented by APCs to T cells, 3) There could be differences in the genetic make up of individuals resulting in less optimal response of the infected keratinocyte to battle HPV. Unfortunately, there is no data available on the immunological response of primary keratinocytes after a genuine HPV infection. A study in which uninfected primary keratinocytes were compared to HPV16 or HPV18 persistently infected primary keratinocytes revealed that persistently present HPV does not strongly affect the expression of the different virus-sensing pathogen recognition receptors expressed by keratincoytes. However, persistent infection was associated with downregulation of: a) components of the antigen presenting pathway, b) the production of antivirals such as type I interferons, c) the production of pro-inflammatory and chemotactic cytokines, and d) components downstream of the pathogen recognition receptors. Notably, many of the downregulated genes are found in a network strongly interconnected by IL- $1 \beta$, a cytokine crucial for the activation of adaptive immunity [72]. Persistent infection also results in downregulation of genes that normally respond to interferon stimulation [73]. One can imagine that small polymorphisms within all these components may determine the innate inflammatory response of the keratinocyte. Hence, it may less effectively suppress viral replication and/or result in a lower production of cytokines and chemokines to attract the adaptive immune system. Not only will it be important to unravel the molecular pathways involved in the keratinocyte's response to HPV infection but also potential alterations in these pathways that may determine the efficacy of these pathways. It has been suggested that HPV also suppresses T-cell activation via the regulation of the function and migration of APCs present in the epithelia as upon pseudo infection of Langerhans cells with HPV16L1L2 virus-like particles the phenotypical and functional maturation of Langerhans cells was suppressed [74,75]. The overall contribution of this effect should be investigated as many healthy and diseased individuals do mount L1-specific immunity suggesting only a minor effect on T-cell priming. In my opinion, there a no apparent defects in the immune system of patients who develop HPV-induced malignancies. Rather these patients are more sensitive to the immune evasion strategies of HPV resulting in a failure to properly stimulate a protective T-cell response to the early antigens of HPV.

The third question relates to the location of HPV-induced malignancies and HPV-specific immunity. An interesting category of tumors in this respect are the squamous cell carcinomas that arise in the head and neck region (HNSCC). Similar to many other tumors, the presence of a strong T-cell associated immune response is also a strong prognostic feature for good clinical outcome in HNSCC. Especially, patients of whom the tumors are infiltrated by high numbers of $\mathrm{CD}^{+} \mathrm{T}$ cells over Tregs display better survival [76-79]. Notably, all most all HPV16+ HNSCC are located in the oropharynx (OSCC) and the majority of these arise in the tonsils. In general, these tumors are heavily infiltrated by immune cells [76-78]. The prognosis of HPV16-induced OSCC is much better than that of their HPV16-negative counterparts as the HPV16+ tumors respond better to chemotherapy and combined chemo-radiation therapy. The 
few reports on HPV16-specific T-cell immunity in HNCSCC describe elevated levels of circulating HPV16 E7-specific $\mathrm{CD}^{+} \mathrm{T}$ cells [80] and the presence of $\mathrm{IgG}$ antibodies to the E6 and E7 oncoproteins in HNSCC patients with high viral load [81]. Although these antibodies are not expected to exert any anti-tumor effect, their presence indicated the active priming of an underlying helper T-cell response. We recently performed a study of the local and systemic immunity in patients with HNSCC and showed that the majority but not all HPV16+ OSCC were infiltrated by functionally different $\mathrm{T}$-cell subsets $\left(\mathrm{CD}^{+} \mathrm{T}\right.$ cells, helper $\mathrm{T}$ cells, regulatory $\mathrm{T}$ cells) that were reactive to HPV16 [82]. In some cases the HPV16-specific effector T cells were highly active in vivo, as reflected by their capacity to respond to immunological stimulation directly ex-vivo after isolation from the tumor (Van der Burg, unpublished data). Although the group of patients studied so far was still small our data suggested that HPV16-specific $\mathrm{T}$ cells were more often locally present in patients with HPV16-positive OSCC than in patients with HPV16+ cervical cancers, in which about one-third of the tumors contained HPV-specific lymphocytes [22]. We speculated that the location of the disease may play a role in this as the majority of OSCC are located within the lymphoid tissue of the tonsils providing ample opportunities for the immune system to respond. This would fit with the outcome of our studies on HPV-specific $\mathrm{T}$ cells in metastasis-positive cervical tumor-draining lymph nodes suggesting that the great majority of tumor-draining lymph nodes contain HPV-specific T-cell reactivity $([21,22]$ and van Poelgeest \& van der Burg, unpublished data).

Despite this it is only $30-40 \%$ of the patients with either HSIL or cancer who develop an HPV-specific T-cell response that can be measured in the blood. In HSIL the presence of circulating HPV-specific $\mathrm{T}$ cells might be explained by the repetitive destructive unsuccessful treatments and persistence of the lesion of those patients displaying T-cell reactivity [19]. One can envisage that the constant present of antigen in combination with inflammation-inducing invasive treatments may result in the activation of an adaptive immune response. In cervical cancer patients the detection of an immune response was related to the depth of invasion of cervical cancer [16]. Is it just the sheer fact that a tumor penetrates normal tissue that allows an immune response to develop? Or is deep invasion associated with a process that creates inflammation allowing the immune system to respond? These questions are important to address as this may lead to new targets for therapy. A clue for specific inflammation at the site of invasion may come from one of the best studied chemokines able to attract myeloid cells and activated $\mathrm{CD} 4^{+}$and $\mathrm{CD} 8^{+} \mathrm{T}$ cells, which is CCL2 also known as monocyte chemotactic protein-1 (MCP-1) [83]. CCL2 is secreted by many immune cells and can also be produced by tumor cells. A good number of cervical cancers were shown to produce CCL2 and - of interest to the above question - it is produced especially at the epithelial-mesenchymal junctions [84-86] suggesting that this may form a key factor in the activation of HPV-specific immunity. Although CCL2 is most known for its attraction of macrophages into tumors, a recent study showed that MCP-1 is required for protective anti-tumor immunity by promoting lymphocyte infiltration into the tumor and subsequent cytokine production [87]. The fact that myeloid cells, compared with T lymphocytes, are more often present in tumors may be the result of reactive nitrogen species produced within the tumor. Reactive nitrogen species induces the nitration of CCL2 and this selectively hinders the attraction of T cells [88]. Elevated levels of nitric oxide have been detected in the plasma of cervical cancer patiensts [89]. A profound understanding of the mechanism through which tumor invasion is associated with the attraction of immune cells will foster the development of new strategies.

The last question is related to tumor-associated macrophages. Are these versatile immune cells our friends or foes? Macrophages are present in virtual all tissues. Circulating monocytes form the main source of macrophages during inflammation and trauma, during which the migration of monoyctes from the bloodstream is dramatically enhanced. Macrophages can rapidly respond to danger signals delivered through pathogen recognition receptors and to stimuli generated by innate and adaptive immune cells. Depending on all different cues in the environment macrophages may adapt to phenotypically different populations of cells with distinct functions. Roughly two distinct polarization states are recognized; the classically activated type 1 macrophages (M1) that are associated with tumor rejection and the alternative activated tumorpromoting type 2 macrophages (M2). Notably, macrophages can easily adapt to another state of activation states ranging between the M1 or M2 phenotype depending on the mix of signals in their direct microenvironment [90].

Based on the use of generally one single marker and the fact that macrophage numbers increased with disease progression, most studies suggest that a high number of tumor associated macrophages is beneficial for tumor growth [91]. However, in non-small cell lung cancer the M1 and M2 polarization of the macrophages was determined revealing that a high $\mathrm{M} 1 / \mathrm{M} 2$ ratio was associated with improved survival [92]. Also in colorectal cancer the type of macrophage determined survival and activation of $\mathrm{T}$ cells $[93,94]$. In cervical cancer immature and mature dendritic cells as well as macrophages at different levels of differentiation are present in stroma and epithelial compartments of HPV-induced cervical cancer [33,95,96]. The numbers of macrophages are increased compared to premalignant lesions of the cervix [97], which would be expected in view of the production of CCL2 especially by cervical cancer cells and less in the premalignant lesions [86]. Some cervical cancers, but not all, can secrete immunomodulatory compounds such as PgE2 and IL-6 $[98,99]$ that have been shown to steer macrophage differentiation towards an M2-like macrophage [96]. The indications that not the macrophage per se but the type of macrophage present may determine tumor infiltration and clinical outcome warrants similar studies in HPV-induced cancers as new therapies are targeting molecular pathways regulating macrophage polarization [100].

In my opinion we are starting to understand the relationship between the immune system, HPV infection and subsequent (pre)malignancies. However, major questions still need to be addressed. The answers undoubtedly will foster the development of new therapies. 


\section{CONFLICT OF INTEREST}

The authors confirm that this article content has no conflict of interest.

\section{ACKNOWLEDGEMENTS}

Declared none.

\section{REFERENCES}

1] Van der Burg SH, Arens R, Melief CJ. Immunotherapy for persistent viral infections and associated disease. Trends Immunol 2011; 32: 97-103.

[2] Van der Burg SH, Palefsky JM. Human Immunodeficiency Virus and Human Papilloma Virus - why HPV-induced lesions do not spontaneously resolve and why therapeutic vaccination can be successful. J Transl Med 2009; 7: 108.

[3] Van der Burg SH, Melief CJ. Therapeutic vaccination against human papilloma virus induced malignancies. Curr Opin Immunol 2011; 23: 252-7.

[4] De Jong A, van Poelgeest MI, van der Hulst JM, et al. Human papillomavirus type 16-positive cervical cancer is associated with impaired CD4+ T-cell immunity against early antigens E2 and E6. Cancer Res 2004; 64: 5449-55.

[5] Nakagawa M, Stites DP, Farhat S, et al. Cytotoxic T lymphocyte responses to E6 and E7 proteins of human papillomavirus type 16: relationship to cervical intraepithelial neoplasia. J Infect Dis 1997; 175: 927-31.

[6] Van den Hende M, van Poelgeest MI, van der Hulst JM, et al. Skin reactions to human papillomavirus (HPV) 16 specific antigens intradermally injected in healthy subjects and patients with cervical neoplasia. Int J Cancer 2008; 123: 146-52.

[7] Kim KH, Greenfield WW, Cannon MJ, Coleman HN, Spencer HJ, Nakagawa M. CD4+ T-cell response against human papillomavirus type 16 E6 protein is associated with a favorable clinical trend. Cancer Immunol Immunother 2011; 6191): 63-70.

[8] Nakagawa M, Stites DP, Patel S, et al. Persistence of human papillomavirus type 16 infection is associated with lack of cytotoxic T lymphocyte response to the E6 antigens. J Infect Dis 2000; 182: 595-8.

[9] Coleman N, Birley HD, Renton AM, et al. Immunological events in regressing genital warts. Am J Clin Pathol 1994; 102: 768-74.

[10] Woo YL, Sterling J, Damay I, et al. Characterising the local immune responses in cervical intraepithelial neoplasia: a crosssectional and longitudinal analysis. Bjog 2008; 115: 1616-21.

[11] Trimble CL, Clark RA, Thoburn C, et al. Human papillomavirus 16-associated cervical intraepithelial neoplasia in humans excludes CD8 T cells from dysplastic epithelium. J Immunol 2010; 185: 7107-14.

[12] Ovestad IT, Gudlaugsson E, Skaland I, et al. Local immune response in the microenvironment of CIN2-3 with and without spontaneous regression. Mod Pathol 2010; 23(9): 1231-40.

[13] Farhat S, Nakagawa M, Moscicki AB. Cell-mediated immune responses to human papillomavirus 16 E6 and E7 antigens as measured by interferon gamma enzyme-linked immunospot in women with cleared or persistent human papillomavirus infection. Int J Gynecol Cancer 2009; 19: 508-12.

[14] Bourgault Villada I, Moyal Barracco M, Ziol M, et al. Spontaneous regression of grade 3 vulvar intraepithelial neoplasia associated with human papillomavirus-16-specific CD4(+) and CD8(+) T-cell responses. Cancer Res 2004; 64: 8761-6.

[15] Seresini S, Origoni M, Lillo F, et al. IFN-gamma produced by human papilloma virus-18 E6-specific CD4+ T cells predicts the clinical outcome after surgery in patients with high-grade cervical lesions. J Immunol 2007; 179: 7176-83.

[16] Heusinkveld M, Welters MJ, van Poelgeest MI, et al. The detection of circulating human papillomavirus-specific $\mathrm{T}$ cells is associated with improved survival of patients with deeply infiltrating tumors. Int J Cancer 2011; 128: 379-89.

[17] Sarkar AK, Tortolero-Luna G, Follen M, Sastry KJ. Inverse correlation of cellular immune responses specific to synthetic peptides from the E6 and E7 oncoproteins of HPV-16 with recurrence of cervical intraepithelial neoplasia in a cross-sectional study. Gynecol Oncol 2005; 99: S251-61.

[18] Van Poelgeest MI, van Seters M, van Beurden M, et al. Detection of human papillomavirus (HPV) 16-specific CD4+ T-cell immunity in patients with persistent HPV16-induced vulvar intraepithelial neoplasia in relation to clinical impact of imiquimod treatment. Clin Cancer Res 2005; 11: 5273-80.

[19] De Vos van Steenwijk PJ, Piersma SJ, Welters MJ, et al. Surgery followed by persistence of high-grade squamous intraepithelial lesions is associated with the induction of a dysfunctional HPV16specific T-cell response. Clin Cancer Res 2008; 14: 7188-95.

Woo YL, van den Hende M, Sterling JC, et al. A prospective study on the natural course of low-grade squamous intraepithelial lesions and the presence of HPV16 E2-, E6- and E7-specific T-cell responses. Int J Cancer 2010; 126: 133-41.

[21] De Vos van Steenwijk PJ, Heusinkveld M, Ramwadhdoebe TH, et al. An unexpectedly large polyclonal repertoire of HPV-specific T cells is poised for action in patients with cervical cancer. Cancer Res 2010, 70: 2707-17.

[22] Piersma SJ, Welters MJ, van der Hulst JM, et al. Human papilloma virus specific $\mathrm{T}$ cells infiltrating cervical cancer and draining lymph nodes show remarkably frequent use of HLA-DQ and -DP as a restriction element. Int J Cancer 2008; 122: 486-94.

[23] Bontkes HJ, de Gruijl TD, Walboomers JM, et al. Assessment of cytotoxic T-lymphocyte phenotype using the specific markers granzyme B and TIA-1 in cervical neoplastic lesions. Br J Cancer 1997; 76:1353-60.

[24] Karim R, Jordanova ES, Piersma SJ, et al. Tumor-expressed B7-H1 and B7-DC in relation to PD-1+ T-cell infiltration and survival of patients with cervical carcinoma. Clin Cancer Res 2009; 15: 63417.

[25] Gooden M, Lampen M, Jordanova ES, et al. HLA-E expression by gynecological cancers restrains tumor-infiltrating CD8 T lymphocytes. Proc Natl Acad Sci USA 2011; 108: 10656-61.

[26] Kobayashi A, Weinberg V, Darragh T, Smith-McCune K. Evolving immunosuppressive microenvironment during human cervical carcinogenesis. Mucosal Immunol 2008; 1: 412-20.

[27] Scott ME, Ma Y, Kuzmich L, Moscicki AB. Diminished IFNgamma and IL-10 and elevated Foxp3 mRNA expression in the cervix are associated with CIN 2 or 3. Int J Cancer 2009; 124: 1379-83.

[28] El-Sherif AM, Seth R, Tighe PJ, Jenkins D. Quantitative analysis of IL-10 and IFN-gamma mRNA levels in normal cervix and human papillomavirus type 16 associated cervical precancer. J Pathol 2001; 195: 179-85.

[29] Syrjanen S, Naud P, Sarian L, et al. Immunosuppressive cytokine Interleukin-10 (IL-10) is up-regulated in high-grade CIN but not associated with high-risk human papillomavirus (HPV) at baseline, outcomes of HR-HPV infections or incident CIN in the LAMS cohort. Virchows Arch 2009; 455: 505-15.

[30] Bais AG, Beckmann I, Lindemans J, et al. A shift to a peripheral Th2-type cytokine pattern during the carcinogenesis of cervical cancer becomes manifest in CIN III lesions. J Clin Pathol 2005; 58: 1096-100.

[31] Levings MK, Bacchetta R, Schulz U, Roncarolo MG. The role of IL-10 and TGF-beta in the differentiation and effector function of T regulatory cells. Int Arch Allergy Immunol 2002; 129: 263-76.

[32] Van der Burg SH, Piersma SJ, de Jong A, et al. Association of cervical cancer with the presence of $\mathrm{CD} 4+$ regulatory $\mathrm{T}$ cells specific for human papillomavirus antigens. Proc Natl Acad Sci USA 2007; 104: 12087-92.

[33] Piersma SJ, Jordanova ES, van Poelgeest MI, et al. High number of intraepithelial CD8+ tumor-infiltrating lymphocytes is associated with the absence of lymph node metastases in patients with large early-stage cervical cancer. Cancer Res 2007; 67: 354-61.

[34] Jaafar F, Righi E, Lindstrom V, et al. Correlation of CXCL12 expression and FoxP3 + cell infiltration with human papillomavirus infection and clinicopathological progression of cervical cancer. Am J Pathol 2009; 175: 1525-35.

[35] Jordanova ES, Gorter A, Ayachi O, et al. Human Leukocyte Antigen Class I, MHC Class I Chain-Related Molecule A, and CD8+/Regulatory T-Cell Ratio: Which Variable Determines Survival of Cervical Cancer Patients? Clin Cancer Res 2008; 14: 2028-35.

[36] Battaglia A, Buzzonetti A, Baranello C, et al. Metastatic tumour cells favour the generation of a tolerogenic milieu in tumour draining lymph node in patients with early cervical cancer. Cancer Immunol Immunother 2009; 58(9): 1363-73.

[37] Wenzel J, Uerlich M, Haller O, Bieber T, Tueting T. Enhanced type I interferon signaling and recruitment of chemokine receptor 
CXCR3-expressing lymphocytes into the skin following treatment with the TLR7-agonist imiquimod. J Cutan Pathol 2005; 32: 25762.

[38] Van Seters M, van Beurden M, ten Kate FJ, et al. Treatment of vulvar intraepithelial neoplasia with topical imiquimod. N Engl J Med 2008; 358: 1465-73.

[39] Terlou A, van Seters M, Kleinjan A, et al. Imiquimod induced clearance of HPV is associated with normalization of immune cell counts in usual type vulvar intraepithelial neoplasia. Int J Cancer 2010; 127(12): 2831-40

[40] Winters U, Daayana S, Lear JT, et al. Clinical and immunologic results of a phase II trial of sequential imiquimod and photodynamic therapy for vulval intraepithelial neoplasia. Clin Cancer Res 2008; 14: 5292-9.

[41] Welters MJ, Kenter GG, de Vos van Steenwijk PJ, et al. Success or failure of vaccination for HPV16-positive vulvar lesions correlates with kinetics and phenotype of induced T-cell responses. Proc Natl Acad Sci USA 2010; 107: 11895-9.

[42] Kenter GG, Welters MJ, Valentijn AR, et al. Vaccination against HPV-16 oncoproteins for vulvar intraepithelial neoplasia. N Engl J Med 2009; 361: 1838-47.

[43] Daayana S, Elkord E, Winters U, et al. Phase II trial of imiquimod and HPV therapeutic vaccination in patients with vulval intraepithelial neoplasia. Br J Cancer 2010; 102: 1129-36.

[44] Kenter GG, Welters MJ, Valentijn AR, et al. Phase I immunotherapeutic trial with long peptides spanning the E6 and E7 sequences of high-risk human papillomavirus 16 in end-stage cervical cancer patients shows low toxicity and robust immunogenicity. Clin Cancer Res 2008, 14: 169-77.

[45] Welters MJ, Kenter GG, Piersma SJ, et al. Induction of tumorspecific CD4+ and CD8+ T-cell immunity in cervical cancer patients by a human papillomavirus type 16 E6 and E7 long peptides vaccine. Clin Cancer Res 2008; 14: 178-87.

[46] Verdegaal EM, Visser M, Ramwadhdoebe TH, et al. Successful treatment of metastatic melanoma by adoptive transfer of bloodderived polyclonal tumor-specific CD4+ and CD8+ T cells in combination with low-dose interferon-alpha. Cancer Immunol Immunother 2011; 60: 953-63.

[47] Rosenberg SA. Cell transfer immunotherapy for metastatic solid cancer-what clinicians need to know. Nat Rev Clin Oncol 2011; 8: $577-85$.

[48] Youde SJ, Dunbar PR, Evans EM, et al. Use of fluorogenic histocompatibility leukocyte antigen-A*0201/HPV 16 E7 peptide complexes to isolate rare human cytotoxic T-lymphocyterecognizing endogenous human papillomavirus antigens. Cancer Res 2000; 60: 365-71.

[49] Nimako M, Fiander A, Wilkinson GWG, Borysiewicz LK, Man S. Human papillomavirus-specific cytotoxic $T$ lymphocytes in patients with cervical intraepithelial neoplasia grade III. Cancer Res 1997; 57: 4855-61.

[50] Bontkes HJ, de Gruijl TD, van den Muysenberg AJ, et al. Human papillomavirus type $16 \mathrm{E} 6 / \mathrm{E} 7$-specific cytotoxic $\mathrm{T}$ lymphocytes in women with cervical neoplasia. Int J Cancer 2000; 88: 92-8.

[51] Ressing ME, van Driel WJ, Celis E, et al. Occasional memory cytotoxic T-cell responses of patients with human papillomavirus type 16-positive cervical lesions against a human leukocyte antigen-A*0201-restricted E7-encoded epitope. Cancer Res 1996; 56: $582-8$

[52] De Jong A, van der Burg SH, Kwappenberg KM, et al. Frequent detection of human papillomavirus 16 E2-specific T-helper immunity in healthy subjects. Cancer Res 2002; 62: 472-9.

[53] Welters MJ, de Jong A, van den Eeden SJ, et al. Frequent display of human papillomavirus type 16 E6-specific memory t-Helper cells in the healthy population as witness of previous viral encounter. Cancer Res 2003; 63: 636-41.

[54] Swain SL, McKinstry KK, Strutt TM. Expanding roles for CD4 T cells in immunity to viruses. Nat Rev Immunol 2012; 12: 136-48.

[55] Sparks-Thissen RL, Braaten DC, Kreher S, Speck SH, Virgin HWt. An optimized CD4 T-cell response can control productive and latent gammaherpesvirus infection. J Virol 2004; 78: 6827-35.

[56] Harandi AM, Svennerholm B, Holmgren J, Eriksson K. Differential roles of B cells and IFN-gamma-secreting CD4(+) T cells in innate and adaptive immune control of genital herpes simplex virus type 2 infection in mice. J Gen Virol 2001; 82: 845-53.

[57] Brien JD, Uhrlaub JL, Nikolich-Zugich J. West Nile virus-specific CD4 $\mathrm{T}$ cells exhibit direct antiviral cytokine secretion and cytotoxicity and are sufficient for antiviral protection. J Immunol 2008; 181: 8568-75.

[58] Iwashiro M, Peterson K, Messer RJ, Stromnes IM, Hasenkrug KJ. CD4(+) $\mathrm{T}$ cells and gamma interferon in the long-term control of persistent friend retrovirus infection. J Virol 2001; 75: 52-60.

[59] Glew SS, Duggan-Keen M, Cabrera T, Stern PL. HLA class II antigen expression in human papillomavirus-associated cervical cancer. Cancer Res 1992; 52: 4009-16.

[60] Heemskerk B, van Vreeswijk T, Veltrop-Duits LA, et al. Adenovirus-specific CD4 $+\mathrm{T}$ cell clones recognizing endogenous antigen inhibit viral replication in vitro through cognate interaction. J Immunol 2006; 177: 8851-9.

[61] Milikan JC, Baarsma GS, Kuijpers RW, Osterhaus AD, Verjans GM. Human ocular-derived virus-specific CD4+ T cells control varicella zoster virus replication in human retinal pigment epithelial cells. Invest Ophthalmol Vis Sci 2009; 50: 743-51.

[62] Bos R, Sherman LA. CD4+ T-cell help in the tumor milieu is required for recruitment and cytolytic function of $\mathrm{CD} 8+\mathrm{T}$ lymphocytes. Cancer Res 2010; 70: 8368-77.

[63] Shepherd PS, Rowe AJ, Cridland JC, Coletart T, Wilson P, Luxton JC. Proliferative T cell responses to human papillomavirus type 16 L1 peptides in patients with cervical dysplasia. J Gen Virol 1996; 77: 593-602.

[64] De Gruijl TD, Bontkes HJ, Walboomers JM, et al. Immune responses against human papillomavirus (HPV) type 16 virus-like particles in a cohort study of women with cervical intraepithelial neoplasia. I. Differential T-helper and IgG responses in relation to HPV infection and disease outcome. J Gen Virol 1999; 80: 399408.

[65] Davidson EJ, Sehr P, Faulkner RL, et al. Human papillomavirus type $16 \mathrm{E} 2-$ and L1-specific serological and T-cell responses in women with vulval intraepithelial neoplasia. J Gen Virol 2003; 84: 2089-97.

[66] Van Poelgeest MI, Nijhuis ER, Kwappenberg KM, et al. Distinct regulation and impact of type 1 T-cell immunity against HPV16 L1, E2 and E6 antigens during HPV16-induced cervical infection and neoplasia. Int J Cancer 2006; 118: 675-83.

[67] Pinto LA, Edwards J, Castle PE, et al. Cellular immune responses to human papillomavirus (HPV)-16 L1 in healthy volunteers immunized with recombinant HPV-16 L1 virus-like particles. J Infect Dis 2003; 188: 327-38.

[68] Hildesheim A, Herrero R, Wacholder S, et al. Effect of human papillomavirus 16/18 L1 viruslike particle vaccine among young women with preexisting infection: a randomized trial. JAMA 2007; 298: 743-53.

[69] Bellone S, El-Sahwi K, Cocco E, Casagrande F, et al. Human papillomavirus type 16 (HPV-16) virus-like particle L1-specific CD8+ cytotoxic T lymphocytes (CTLs) are equally effective as E7specific CD8+ CTLs in killing autologous HPV-16-positive tumor cells in cervical cancer patients: implications for L1 dendritic cellbased therapeutic vaccines. J Virol 2009; 83: 6779-89.

[70] Yan M, Peng J, Jabbar IA, et al. Despite differences between dendritic cells and Langerhans cells in the mechanism of papillomavirus-like particle antigen uptake, both cells cross-prime T cells. Virology 2004; 324: 297-310.

[71] Visser J, van Baarle D, Hoogeboom BN, et al. Enhancement of human papilloma virus type $16 \mathrm{E} 7$ specific $\mathrm{T}$ cell responses by local invasive procedures in patients with (pre)malignant cervical neoplasia. Int J Cancer 2006; 118: 2529-37.

[72] Karim R, Meyers C, Backendorf C, et al. Human Papillomavirus Infection Deregulates the Response of a Cellular Network Comprising of Chemotactic and Proinflammatory Genes. PloS One 2011; 6(3): e17848

[73] Chang YE, Laimins LA. Microarray analysis identifies interferoninducible genes and Stat-1 as major transcriptional targets of human papillomavirus type 31. J Virol 2000; 74: 4174-82.

[74] Fausch SC, Da Silva DM, Rudolf MP, Kast WM. Human papillomavirus virus-like particles do not activate Langerhans cells: a possible immune escape mechanism used by human papillomaviruses. J Immunol 2002; 169: 3242-9.

[75] Fahey LM, Raff AB, Da Silva DM, Kast WM. A major role for the minor capsid protein of human papillomavirus type 16 in immune escape. J Immunol 2009; 183: 6151-6.

[76] Thurlow JK, Pena Murillo CL, Hunter KD, et al. Spectral clustering of microarray data elucidates the roles of microenvironment remodeling and immune responses in survival of 
head and neck squamous cell carcinoma. J Clin Oncol 2010; 28: 2881-8.

[77] Wansom D, Light E, Thomas D, et al. Infiltrating lymphocytes and human papillomavirus-16-associated oropharyngeal cancer. Laryngoscope 2012; 122: 121-7.

[78] Kong CS, Narasimhan B, Cao H, et al. The relationship between human papillomavirus status and other molecular prognostic markers in head and neck squamous cell carcinomas. Int J Radiat Oncol Biol Phys 2009; 74: 553-61.

[79] Hirota J, Ueta E, Osaki T, Ogawa Y. Immunohistologic study of mononuclear cell infiltrates in oral squamous cell carcinomas. Head Neck 1990; 12: 118-25.

[80] Albers A, Abe K, Hunt J, et al. Antitumor activity of human papillomavirus type $16 \mathrm{E} 7$-specific $\mathrm{T}$ cells against virally infected squamous cell carcinoma of the head and neck. Cancer Res 2005; 65: 11146-55.

[81] Kreimer AR, Clifford GM, Snijders PJ, et al. HPV16 semiquantitative viral load and serologic biomarkers in oral and oropharyngeal squamous cell carcinomas. Int J Cancer 2005; 115: 329-32.

[82] Heusinkveld M, Goedemans R, Briet RJ, et al. Systemic and local human papillomavirus 16-specific T-cell immunity in patients with head and neck cancer. Int J Cancer 2011; 131(2): E74-85.

[83] Carr MW, Roth SJ, Luther E, Rose SS, Springer TA. Monocyte chemoattractant protein 1 acts as a T-lymphocyte chemoattractant. Proc Natl Acad Sci USA 1994; 91: 3652-6.

[84] Hazelbag S, Fleuren GJ, Baelde JJ, Schuuring E, Kenter GG, Gorter A. Cytokine profile of cervical cancer cells. Gynecol Oncol 2001; 83: 235-43.

[85] Riethdorf L, Riethdorf S, Gutzlaff K, Prall F, Loning T. Differential expression of the monocyte chemoattractant protein-1 gene in human papillomavirus-16-infected squamous intraepithelial lesions and squamous cell carcinomas of the cervix uteri. Am J Pathol 1996; 149: 1469-76.

[86] Kleine-Lowinski K, Gillitzer R, Kuhne-Heid R, Rosl F. Monocytechemo-attractant-protein-1 (MCP-1)-gene expression in cervical intra-epithelial neoplasias and cervical carcinomas. Int $\mathrm{J}$ Cancer 1999; 82: 6-11.

[87] Nakasone Y, Fujimoto M, Matsushita T, et al. Host-derived MCP-1 and MIP-1alpha regulate protective anti-tumor immunity to localized and metastatic B16 melanoma. Am J Pathol 2012; 180: 365-74.

[88] Molon B, Ugel S, Del Pozzo F, et al. Chemokine nitration prevents intratumoral infiltration of antigen-specific $\mathrm{T}$ cells. J Exp Med 2011; 208: 1949-62.

[89] Beevi SS, Rasheed MH, Geetha A. Evidence of oxidative and nitrosative stress in patients with cervical squamous cell carcinoma. Clin Chim Acta 2007; 375: 119-23.
[90] Heusinkveld M, van der Burg SH. Identification and manipulation of tumor associated macrophages in human cancers. J Transl Med 2011; 9: 216.

[91] Bingle L, Brown NJ, Lewis CE. The role of tumour-associated macrophages in tumour progression: implications for new anticancer therapies. J Pathol 2002; 196: 254-65.

[92] Ohri CM, Shikotra A, Green RH, Waller DA, Bradding P Macrophages within NSCLC tumour islets are predominantly of a cytotoxic M1 phenotype associated with extended survival. Eur Respir J 2009; 33: 118-26.

[93] Algars A, Irjala H, Vaittinen SH, et al. Type and location of tumorinfiltrating macrophages and lymphatic vessels predict survival of colorectal cancer patients. Int J Cancer 2011; 131(4): 864-73.

[94] Ong SM, Tan YC, Beretta O, et al. Macrophages in human colorectal cancer are pro-inflammatory and prime $\mathrm{T}$ cells towards an anti-tumour type-1 inflammatory response. Eur J Immunol 2012; 42: 89-100.

[95] Zijlmans HJ, Fleuren GJ, Baelde HJ, Eilers PH, Kenter GG, Gorter A. Role of tumor-derived proinflammatory cytokines GM-CSF, TNF-alpha, and IL-12 in the migration and differentiation of antigen-presenting cells in cervical carcinoma. Cancer 2007; 109: 556-65.

[96] Heusinkveld M, de Vos van Steenwijk PJ, Goedemans R, et al. M2 macrophages induced by prostaglandin E2 and IL-6 from cervical carcinoma are switched to activated M1 macrophages by CD4+ Th1 cells. J Immunol 2011; 187: 1157-65.

[97] Hammes LS, Tekmal RR, Naud P, et al. Macrophages, inflammation and risk of cervical intraepithelial neoplasia (CIN) progression--clinicopathological correlation. Gynecol Oncol 2007, 105: 157-65.

[98] Herfs M, Herman L, Hubert P, et al. High expression of PGE2 enzymatic pathways in cervical (pre)neoplastic lesions and functional consequences for antigen-presenting cells. Cancer Immunol Immunother 2009; 58: 603-14

[99] Srivani R, Nagarajan B. A prognostic insight on in vivo expression of interleukin-6 in uterine cervical cancer. Int J Gynecol Cancer 2003; 13: 331-9.

[100] Ruffell B, Affara NI, Coussens LM. Differential macrophage programming in the tumor microenvironment. Trends Immunol 2012; 33: 119-26.

[101] Hildesheim A, Wang SS. Host and viral genetics and risk of cervical cancer: a review. Virus Res 2002; 89(2): 229-40.

[102] Madeleine MM, Johnson LG, Smith AG, et al. Comprehensive analysis of HLA-A, HLA-B, HLA-C, HLA-DRB1, and HLADQB1 loci and squamous cell cervical cancer risk. Cancer Res 2008; 68(9): 3532-9.

(C) Sjoerd H. van der Burg; Licensee Bentham Open.

This is an open access article licensed under the terms of the Creative Commons Attribution Non-Commercial License (http: //creativecommons.org/licenses/by$\mathrm{nc} / 3.0 /$ ) which permits unrestricted, non-commercial use, distribution and reproduction in any medium, provided the work is properly cited. 